Abstract P070 Table 1 Frequency of chemsex consultations reported by English clinics split into urban/rural category ( $\mathrm{n}=$ number of clinics):

\begin{tabular}{llllll}
\hline $\begin{array}{l}\text { Frequency of Chemsex } \\
\text { Consultations }\end{array}$ & $\begin{array}{l}\text { Group A clinics } \\
\text { (urban conurbation) } \mathbf{n}(\%)\end{array}$ & $\begin{array}{l}\text { Group B clinics } \\
\text { (Urban + city/town) } \mathbf{n}(\%)\end{array}$ & $\begin{array}{l}\text { Group C Clinics } \\
\text { (Urban + rural) } \mathbf{n}(\%)\end{array}$ & $\begin{array}{l}\text { Group D clinics } \\
\text { (Non-urban) } \mathbf{n}(\%)\end{array}$ & $\begin{array}{l}\text { Total } \mathbf{n} \\
\text { P value }\end{array}$ \\
\hline Never & $7(19 \%)$ & $5(12.5 \%)$ & $3(30 \%)$ & $4(27 \%)$ & 19 \\
Monthly or less & $16(44 \%)$ & $28(70 \%)$ & $5(50 \%)$ & $8(53 \%)$ & 57 \\
Weekly & $10(28 \%)$ & $5(12.5 \%)$ & $2(20 \%)$ & $3(20 \%)$ & 20 \\
At least daily & $3(8 \%)$ & $2(5 \%)$ & 0 & 0 & 5 \\
Total & 36 & 40 & 10 & 15 & 101 \\
\hline
\end{tabular}

Background/introduction Sexualised substance use (chemsex) amongst men who have sex with men is well documented in some areas (London, Brighton, Manchester), and associated with high-risk sexual practices and acquisition of sexually transmitted infections.

Aim(s)/objectives To explore demand for chemsex services in UK GUM clinics, including outside major conurbations

Methods An online survey was distributed to clinical staff in GUM clinics across the UK. Analysis at clinic level was undertaken for England, with clinics split into 4 categories: (A) urban conurbation, (B) urban with city/town, (C) urban with significant rural, and (D) non-urban.

Results 357 individuals responded from 152 clinics, 90\% were from England. Country-specific clinic response rates were $63 \%$ $(135 / 214)$ in England, 80\% (4/5) Northern Ireland (NI), 8\% (3/ 39) Scotland and $83 \%(10 / 12)$ Wales. $82 \%(227 / 278)$ of respondents reported seeing patients who disclosed chemsex (82\% England (205/251), 83\% NI (5/6), 75\% Scotland (6/8), $85 \%$ Wales (11/13)), and there was broad consensus that chemsex services (86\%) and training were needed (98\%). 64\% (68/ 106) of clinics reported routinely asking selected patients about chemsex, 10\% (11/106) asked all patients, and the remainder did not ask. Although the proportion of clinics seeing chemsex and the frequency of chemsex consultations was reported to be higher in more urban settings, differences were not significant and many clinics in rural areas reported chemsex consultations (Table 1).

Discussion/conclusion Chemsex consultations occur in most GUM clinics across the UK albeit to varying degrees. These data suggest a widespread need for specialist chemsex services and training.

\section{P071 COST EFFICACY SAVINGS ON SEROLOGICAL FOLLOW UP FOR SYPHILIS AT AN URBAN SEXUAL HEALTH CLINIC}

Rebecca Gilson. Chalmers Centre, Edinburgh, UK

\subsection{6/sextrans-2016-052718.125}

Background/introduction General Practitioners (GPs) in Lothian are requesting syphilis serology in $65 \%$ of individuals being tested for HIV. Adding syphilis to the remaining 35\% would cost around $£ 7000$. In Edinburgh full serology (IgG, RPR, TPPA, IgM) is performed in all with a previous syphilis diagnosis. HIV positive individuals are tested 6 monthly. BASHH 2015 Syphilis Guidelines recommend RPR follow up and annual monitoring in HIV positive individuals. The aim was to evaluate if full serological screening was appropriate and whether cost savings could be made.

Methods One hundred individuals with full serological testing for syphilis, 30/9/15 to 29/10/15. Age, risk group, HIV status, stage of infection, PCR, treatment, symptoms, follow up and infection risks were collated.

Results 88 male, 12 female. Twenty one early infection (all positive RPR), 4 re infection (all rise in RPR), 7 late latent and 54 treated infection. Forty seven HIV positive. Of these 14 (21\%) had no ongoing risks and 16 (34\%) had ongoing risks, longstanding RPR 0. Forty HIV negative. Twenty four (60\%) were MSM with treated STS, and a longstanding RPR 0.

Recommendations Testing should be annual RPR in HIV positive individuals with no ongoing risks. In those with ongoing risks RPR alone sufficient for monitoring. All with re infection would have been picked up on RPR. In HIV negative individuals, most had ongoing risks but a longstanding RPR 0 . Monitoring with RPR only would have diagnosed all re infections.

Discussion It was difficult to vary testing based on risk assessment and concerns that RPR only may miss prozone. However, there was agreement that IgM should no longer be performed. At $£ 3.77 /$ test approximately $£ 377 /$ month would be saved in this group alone. This would apply to all other testing with considerable cost savings

\section{P072 EQUITY OF ACCESS TO ONLINE SEXUALLY TRANSMITTED INFECTION SELF-SAMPLING SERVICES IN LAMBETH AND SOUTHWARK: AN EARLY VIEW OF THE DATA}

${ }^{1}$ Sharmani Barnard*, ${ }^{2}$ Katy Turner, ${ }^{2}$ Katherine Looker, ${ }^{1}$ loannis Bakolis, ${ }^{3}$ Caroline Free, ${ }^{1}$ Paula Baraitser. 'King's College London, London, UK; ' University of Bristol, Bristol, UK; ${ }^{3}$ London School of Hygiene and Tropical Medicine, London, UK

10.1136/sextrans-2016-052718.126

Background In 2015, free access to online services for STI selfsampling was made available to residents in Lambeth and Southwark. Little is known about who accesses online services within these boroughs and whether access is equitable between demographic groups.

Aims To describe the demographic factors associated with use of online services for STI self-sampling.

Methods A cross-sectional analysis of routinely collected data from April to October 2015 for online and sexual health clinics in Lambeth and Southwark. We included residents who attended sexual health clinics or used online sexual health services for basic STI testing and were over the age of 16 . Data were analysed by means of logistic regression.

Results A total of 9,496 basic STI testing services were delivered, 6,697 (70.52\%) were delivered in clinics while 2,799 $(29.48 \%)$ were delivered online. Descriptive data for service use by demographic group is available in Table 1 . When compared to residents aged 16-20 years old, residents aged 21-24 $(\mathrm{OR}=1.93, \mathrm{p} \leq 0.001)$, and $25-30(\mathrm{OR}=2.17, \mathrm{p} \leq 0.001)$ 
were more likely to use online services than clinic services. Females were more likely to use online services than clinic services when compared to males $(\mathrm{OR}=1.55, \mathrm{p} \leq 0.001)$. When compared to residents of white ethnicity, residents who identified as Asian $(\mathrm{OR}=0.74, \mathrm{p}=0.04)$, Black $(\mathrm{OR}=0.43$, $\mathrm{p} \leq 0.001)$ or Other $(\mathrm{OR}=0.48, \mathrm{p} \leq 0.001)$ were less likely to use online services than clinic services. When compared with heterosexuals, homosexuals $(\mathrm{OR}=1.46, \mathrm{p} \leq 0.001)$ and bisexuals $(\mathrm{OR}=3.10, \mathrm{p} \leq 0.001)$ were more likely to use online services than clinic services.

Conclusion There are demographic differences between residents that access online services and those that access clinic services. These data and more up to date data will be presented at the conference.

\begin{tabular}{|c|c|c|c|c|}
\hline $\begin{array}{l}\text { Demographic } \\
\text { variable }\end{array}$ & $\begin{array}{l}\text { Clinic users } \\
\text { n (\%) }\end{array}$ & $\begin{array}{l}\text { Online users } \\
\mathrm{n}(\%)\end{array}$ & $\begin{array}{l}\text { Total } \\
\mathrm{n}\end{array}$ & $\begin{array}{l}p \text { value } \\
\left(X^{2}\right)\end{array}$ \\
\hline \multicolumn{5}{|l|}{ Ethnicity } \\
\hline \multirow[t]{2}{*}{ White } & 3,285 & 1,939 & 5,224 & $<0.001$ \\
\hline & (62.88) & (37.12) & & \\
\hline Mixed & $369(59.23)$ & $254(40.77)$ & 623 & \\
\hline Asian & $172(71.07)$ & $70(28.93)$ & 242 & \\
\hline \multirow[t]{2}{*}{ Black } & 1,991 & $442(18.17)$ & 2,433 & \\
\hline & $(81.83)$ & & & \\
\hline Other & $360(79.30)$ & $94(20.70)$ & 454 & \\
\hline Not Known & $516(100.00)$ & $0(0.00)$ & 516 & \\
\hline \multicolumn{5}{|l|}{ Age group } \\
\hline $16-20$ & 717 (80.02) & 179 (19.98) & 896 & $<0.001$ \\
\hline \multirow[t]{2}{*}{$21-25$} & 1,664 & 855 (33.94) & 2,519 & \\
\hline & (66.06) & & & \\
\hline \multirow[t]{2}{*}{$26-30$} & 1,726 & 1,001 & 2,727 & \\
\hline & (63.29) & (36.71) & & \\
\hline \multirow[t]{2}{*}{$31-35$} & 1,067 & $408(27.66)$ & 1,475 & \\
\hline & (72.34) & & & \\
\hline \multirow[t]{2}{*}{$36+$} & 1,523 & $356(18.95)$ & 1,879 & \\
\hline & $(81.05)$ & & & \\
\hline \multicolumn{5}{|l|}{ Gender } \\
\hline \multirow[t]{2}{*}{ Male } & 3,107 & 1,036 & 4143 & $<0.001$ \\
\hline & (74.99) & $(25.01)$ & & \\
\hline \multirow[t]{2}{*}{ Female } & 3,590 & 1,763 & 5,353 & \\
\hline & $(67.07)$ & $(32.93)$ & & \\
\hline \multicolumn{5}{|c|}{ Sexual orientation } \\
\hline \multirow[t]{2}{*}{ Heterosexual } & 5,439 & 2,268 & 7,707 & $<0.001$ \\
\hline & $(70.57)$ & $(29.43)$ & & \\
\hline Homosexual & 927 (70.28) & $392(29.72)$ & 1,319 & \\
\hline Bisexual & $109(43.95)$ & $139(56.05)$ & 248 & \\
\hline Unknown & $222(100.00)$ & $0(0.00)$ & 222 & \\
\hline \multirow[t]{2}{*}{ Total } & 6,697 & 2,799 & 9,496 & \\
\hline & (70.52) & (29.48) & & \\
\hline
\end{tabular}

\section{P073 IF HIV-PREP IS MADE AVAILABLE IN ENGLAND, WHAT ARE THE RESOURCE IMPLICATIONS FOR GUM CLINIC SERVICE PROVIDERS?}

Koh Jun Ong*, Nigel Field, Holly Mitchell, Sarika Desai, O Noel Gill. Public Health England, London, UK

10.1136/sextrans-2016-052718.127
Background Under plausible assumptions, HIV-pre-exposure prophylaxis (HIV-PrEP) is cost-effective for high-risk MSM in England. There is consensus that HIV-PrEP should be delivered via quarterly GUM clinic attendances. BASHH recommends quarterly STI screening for high-risk MSM. An HIV-PrEP policy would have direct (extra consultation time and renal function tests) and indirect (additional STI/HIV screening) GUM clinic resource implications, as well as drug costs.

Aims To explore clinic costs if HIV-PrEP is introduced.

Methods Indirect clinic costs per person per year (PPPY) used the draft $2016 / 17$ National Tariff ( $£ 104 /$ follow-up GUM visit). Direct HIV-PrEP-specific clinic costs were estimated by microcosting. Direct tenofovir/emtricitabine costs used BNF prices ( $£ 12 /$ tablet), assuming $50 \% / 50 \%$ daily/intermittent dosing. GUMCADv2 provided numbers of eligible MSM and likely additional clinic attendances.

Results MSM, clinically assessed as high-risk, currently attend GUM services twice/year (median); for those given PrEP, two additional attendances would be required annually with indirect costs of $£ 208$ PPPY. In year one, the direct cost of starting HIVPrEP would be $£ 176$ PPPY, including an additional month- 1 follow-up. Clinical risk-assessment should result in offering HIVPrEP to 8,000 high-risk MSM annually. There is considerable turnover in this group, with $<10 \%$ remaining high-risk after two years. Assuming steady increases in coverage (from 2,000 in year one to 5,000 by year four), direct and indirect clinic costs would be $£ 0.8 \mathrm{M}-£ 2 \mathrm{M} /$ year and drug costs $£ 8 \mathrm{M}-£ 20 \mathrm{M} /$ year.

Discussion A national HIV-PrEP programme is likely to incur large drug costs but limited clinic costs. A substantially reduced drug price will be needed to enable wide coverage and maximise population impact.

\section{P074 BARRIERS ASSOCIATED WITH THE IMPLEMENTATION OF PROGRAMS FOR THE PREVENTION OF VERTICAL TRANSMISSION OF HIV}

${ }^{1,3}$ A.A.I.N Jayasekara*, ${ }^{2}$ D.A.C.L Dalugama, ${ }^{2}$ W.M.S.N.K Nawarathne, ${ }^{2}$ K.M.N.G.N Dias, ${ }^{3}$ O.B.W Rajapakse, ${ }^{2}$ S.D Dharmarathne. ${ }^{1}$ Brighton and Sussex University Hospitals, Brighton, UK; ${ }^{2}$ Faculty of Medicine, University of Peradeniya, Peradeniya, Sri Lanka; ${ }^{3}$ Faculty of Medicine, University of Sri Jayawardhanapura, Nugegoda, Sri Lanka, National STD control programme, Colombo, Sri Lanka

\subsection{6/sextrans-2016-052718.128}

Background Implementation of programs for the Prevention of Vertical Transmission of HIV(PVTHIV)/PMTCT faces higher degree of barriers and challenges at different levels.

Objective This pilot study is to examine the potential barriers that might affect the acceptability of interventions for in rural estate health care settings in Sri Lanka.

Methodology This is a cross-sectional study conducted among pregnant women in tea plantations where there are no programs for PVTHIV.

Results Of the 404 participants, 81\% (324/404) were tea estate workers, while 80 (19\%) were from nearby villages. Literacy rate among the respondents was high (88\%). Only 16\% knew about HIV/AIDS, 381 (95\%) did not know that a mother with HIV can pass the virus to her child and 390 (97\%) did not aware that HIV can transmit through breast milk. More than 95\% of participants agreed that they have enough access to basic antenatal care, including institutional delivery plan but none were aware of PMTCT services. Acceptability of a HIV test was high with $87 \%$ (337/404). Out of the women living with their marital partners (398/404,98\%), 68\% (264/398) preferred to 